\title{
A complementaridade de um diálogo entre Paulo Freire e Edgar Morin
}

\author{
Maximina Maria Freire* \\ Karin Claudia Nin Brauer**
}

\section{Resumo}

No ano em que se comemora o centenário de nascimento (1921-2021) de Paulo Freire e de Edgar Morin, expoentes universais do pensamento humano, influentes na vida e na educação dos séculos XX e XXI, nosso objetivo é, neste artigo, promover um diálogo epistemológico entre esses autores, discutindo, primeiramente, o significado dos conceitos freirianos de leitura e palavramundo, e a preocupação moriniana pelo conhecimento e sua organização, o pensamento complexo e a construção do conhecimento pertinente. Apresentados os autores e seus argumentos, articulamos os construtos que distinguem cada um, evidenciando em que dimensão a proposta libertadora de Freire se conecta ao pensamento complexo de Morin, enredando uma teia dinâmica na qual emancipação se embasa no saber pertinente que, em um ciclo recursivo, promove transformação e libertação.

Palavras-chave: Leitura; Palavramundo; Conhecimento Pertinente; Pensamento Complexo.

\section{Abstract}

In the year that is celebrated Paulo Freire's and Edgar Morin's birth centenary (1921-2021), universal exponents of human thought, influential in the life and education of the 20th and 21 st centuries, our objective in this article is to promote an epistemological dialogue between these authors, discussing, first, the meaning of the Freirian concepts of reading and wor-

* Pontifícia Universidade Católica de São Paulo, PUC-SP, São Paulo, Brasil. mmfreire@uol.com.br. Orcid: https://orcid.org/0000-0002-7908-1143

** Instituto Federal de Educação Ciência e Tecnologia de São Paulo, IFSP, São Paulo, Brasil. kcnb76@gmail.com. Orcid: https://orcid.org/0000-00018581-9012 
d-world, and the Morinian concern for knowledge and its organization, the complex thinking and the construction of pertinent knowledge. After presenting the authors and their arguments, we articulate the constructs that distinguish each one, showing in what dimension Freire's liberating proposal is connected to Morin's complex thinking, entangling a dynamic net in which emancipation is based on the pertinent knowledge that, in a recursive cycle, promotes transformation and liberation.

Keywords: Reading; Word-world; Pertinent knowledge; Complex Thinking.

\section{Resumen}

En el año que se celebra el centenario del nacimiento (1921-2021) de Paulo Freire y Edgar Morin, exponentes universales del pensamiento humano, influyentes en la vida y la educación de los siglos XX y XXI, nuestro objetivo en este artículo es promover un diálogo epistemológico entre estos autores, discutiendo, en primer lugar, el significado de los conceptos freireianos de lectura y de la palabramundo, y la preocupación moriniana por el conocimiento y su organización, el pensamiento complejo y la construcción del conocimiento pertinente. Presentados los autores y sus argumentos, articulamos los constructos que distinguen a cada uno, mostrando en que dimensión se conecta la propuesta liberadora de Freire con el pensamiento complejo de Morin, entrelazando una red dinámica en la que la emancipación se fundamenta en el conocimiento pertinente que, en un ciclo recursivo, promueve la transformación y la liberación.

Palabras clave: Lectura; Palabramundo; Conocimiento pertinente; Pensamiento Complejo.

\section{Introdução}

A forma como o ser humano lê o mundo, constrói conhecimento ${ }^{1}$, emprega e valoriza o que aprende em relação a si próprio, aos outros, ao mundo e ao próprio conhecimento está constantemente marcada pelo diálogo e pela conexão de diferentes saberes, assim como por incertezas e contradições. Em um cenário de curiosidades, imprevisibilidades e reflexões, surgem, entre tantos, questionamentos sobre como compreender o mundo, como conhecer o conhecimento, que conhecimento é pertinente, como ser

Neste artigo, assumimos os termos conhecimento e saberes como sinônimos. 
autônomo a partir dos saberes construídos, como se transformar e emancipar, como ser cidadão, como ser um cidadão planetário.

Indagações como essas motivam este artigo que tem por objetivo promover um diálogo epistemológico entre Paulo Freire e Edgar Morin, no ano em que, coincidentemente, se comemora o centenário de nascimento desses dois expoentes universais, influentes na vida, no pensamento e na educação dos séculos XX e XXI. Partimos de uma reflexão sobre o significado dos conceitos freireanos de leitura e palavramundo, e seguimos discutindo a preocupação moriniana com o conhecimento e sua organização, o pensamento complexo e a construção do conhecimento pertinente. Esses autores, contemporâneos na maior parte de suas vidas, embora vivessem em países distintos, revelam preocupação similar em relação à construção de saberes contextualizados/ecologizados, partindo de referências prévias do sujeito, de sua vida e de sua realidade local/ global. Considerando essas variáveis, propõem rumos ora convergentes, ora divergentes, revelando vias pertinentes para o conhecimento, a educação, o sujeito e suas ações.

Para atingir o objetivo proposto neste artigo, apresentamos, inicialmente, a ótica de Freire, para depois particularizar o olhar em Morin e, então, aproximarmos as duas visões, traçando um paralelo entre esses interlocutores que se situam em um cenário transdisciplinar. Ressaltamos que a relevância dessa proposta está em levar linguistas aplicados, educadores e interessados nessas áreas e em áreas afins a reflexões transversais e transdisciplinares que articulem, entre outras, os campos da Linguística Aplicada, da Pedagogia Crítica e da Epistemologia da Complexidade.

\section{A leitura e a palavramundo sob a via freireana}

Freire, um educador político - ou, para muitos, um político educador -, lê o mundo, escreve e age em prol da libertação e da autonomia dos sujeitos que, inicialmente, percebe como oprimidos. Desse modo, para ele (FREIRE, 1999), a autonomia ocorre como expressão da historicidade de homens e mulheres. Não há auto- 
nomia no abstrato, assim como, não há ser humano a não ser que esteja ligado à história. O sujeito histórico freireano se constitui nas diferentes lutas que aconteceram em prol da conquista pela sua humanidade. Freire era apaixonado pelo ser humano, um humanista, como o percebia Ana Maria Araújo Freire (2015, p.291):

\begin{abstract}
Dadivosamente, não se fixou na mesquinhez humana, ao contrário, procurou a grandeza ontológica de homens e de mulheres, mesmo sabendo das fragilidades destes e destas, e, portanto, das dele também. Tolerantemente respeitou os diferentes dele mesmo, como também os seus antagônicos, obviamente, sem dar a esses e a essas os créditos de valor aos seus pensamentos e ações, como deu aos seus diferentes e a si próprio. Assim, fez-se sabiamente um humanista.
\end{abstract}

Freire (2002) preocupa-se com o desenvolvimento da consciência crítica, caracterizada por uma visão questionadora que tinha como proposta não se posicionar na superficialidade, mas investigar os problemas de maneira detalhada, profunda. Ele considera que o exercício do espírito crítico possibilita ao ser humano transformar a realidade. Deste modo, por meio da consciência crítica, o sujeito pode compreender melhor o contexto em que se encontra, ultrapassando os limites imediatos da sala de aula e fazendo uma nova leitura da realidade. Assim, se faz necessário que educadores e educandos se coloquem criticamente ao vivenciarem a educação, negando sua neutralidade e transcendendo posturas ingênuas.

O educador tece argumentos "sobre a prática educativo-progressista em favor da autonomia do ser educando" (FREIRE, 2002 , p. 14). Para ele, essa prática só se viabiliza com uma formação docente que seja coerente com seus pressupostos, exigindo: rigor metódico, pesquisa, respeito aos saberes dos educandos, criticidade, ética e estética, corporificação de palavras pelo exemplo, reflexão crítica sobre a prática, reconhecimento e assunção da identidade cultural, conscientização do inacabamento, respeito à autonomia do ser educando, bom senso, humildade, tolerância, convicção de que mudar é possível, curiosidade e competência profissional. 
A proposta teórico-pedagógica de Freire (2002) é construída sobre a base da ação reflexiva e dialógica e se profere como probabilidade de transformação da pessoa e da sociedade, é uma proposta de educação emancipadora que abrange um compromisso político e tem como pressuposto a luta contra a opressão e dominação. Assim, a educação freiriana dá ênfase para a conscientização do ser político, para a compreensão de sua função como cidadão, tendo uma postura crítica e política na sociedade, valorizando sua vivência, cultura e história. Perceber-se como oprimido e libertar-se dessa condição é a premissa que Freire (2013, p.31) defende:

\begin{abstract}
Quem, melhor que os oprimidos, se encontrará preparado para entender o significado terrível de uma sociedade opressora? Quem sentirá, melhor que eles, os efeitos da opressão? Quem, mais que eles, para ir compreendendo a necessidade da libertação? Libertação a que não chegarão pelo acaso, mas pela práxis de sua busca; pelo conhecimento e reconhecimento da necessidade de lutar por ela. "Luta que, pela finalidade que lhe derem os oprimidos, será um ato de amor, com o qual se oporão ao desamor contido na violência dos opressores, até mesmo quando esta se revista da falsa generosidade referida." (grifo do autor).
\end{abstract}

A educação também aparece como condicionamento ético, o que denomina de "ética universal do ser humano" (FREIRE, 2002, p. 16). Essa questão ética se materializa na consolidação de uma educação libertadora, proporcionando condições, para estudantes e para educadores, de se considerarem sujeitos de sua própria história e de construir uma sociedade justa, igualitária, libertando-se desse modo, das formas de opressão e exclusão sociais. A partir dessa visão, o ser humano faz uma leitura mais profunda de si e do seu contexto, ligada às suas reais necessidades.

Conforme afirma Freire (1992), desenvolver o ato de ler, escrever e alfabetizar-se é, a princípio, aprender a ler o mundo, entender o seu contexto, numa relação que liga a linguagem e a realidade. Considerando essa premissa para alfabetizar, Freire (1992) criou o neologismo palavramundo que representa o conhecimento que o sujeito traz de seu contexto. Constitui uma prática alfabetizadora 
pautada no exercício da curiosidade e da apreensão do significado e do sentido existencial da palavra, no mundo, com o mundo, ou seja, na vida cotidiana de cada educando.

Essa interculturalidade oportuniza não apenas a interação, mas também a parceria entre professor-aluno e aluno-aluno, possibilitando que todos desenvolvam o conhecimento por meio do compartilhamento de experiências. Além disso, incluir na alfabetização dos educandos palavras do seu dia-a-dia, certamente os envolve e desperta neles um interesse diferenciado em aprender.

Nesse viés, o educador (FREIRE, 1992, p.11-12) ainda menciona que:

A leitura do mundo precede a leitura da palavra, daí que a posterior leitura desta não pode prescindir da continuidade da leitura daquele (a palavra que eu digo sai do mundo que estou lendo, mas a palavra que sai do mundo que eu estou lendo vai além dele).

Freire (1992) nos leva à reflexão de que o mundo que se mobiliza para o sujeito, em seu contexto, pode ser distinto do mundo da escolarização. Dessa maneira, a leitura das palavras na escolarização, ou de sua escrita, podem estar distantes da leitura da realidade desse sujeito. Assim, Freire trabalhava com textos e palavras do contexto vivenciado pelo aluno, ou seja, significativo para ele e essa atitude desenvolvia no indivíduo sua percepção e seu aprendizado. Desse modo, a compreensão ocorria por uma relação direta entre o concreto e o (s) sujeito(s), por meio de elementos que lhe eram familiares.

Essa forma de desenvolver a leitura proposta por Freire, busca a percepção crítica, a interpretação e a escrita do que foi lido pelo estudante, construindo conhecimento que se torna significativo, pertinente, pois parte da realidade do aluno. De tal modo, a proposição de Freire (1997) enfatiza que o conhecimento não se transmite, se constrói. O papel do educador nessa proposta é fundamental, da mesma forma que a coerência entre o que o educador declara e de sua prática. 
Freire (2005, p.55) procura, então, despertar no sujeito, o lado ativo do ser, lutar pela autonomia, libertação e conscientização do estar no mundo:

Estar com o mundo resulta de sua abertura à realidade [...] há uma pluralidade nas relações do homem com o mundo, na medida em que responde à ampla variedade de desafios. Em que não se esgota um tipo padronizado de resposta. A sua pluralidade não é só em face dos diferentes desafios que partem do seu contexto, mas em face de um mesmo desafio. No jogo constante de suas respostas, altera-se no próprio ato de responder. Organiza-se. Testa-se. Age. Faz tudo isso com a certeza de quem usa uma ferramenta.

O excerto acima ilustra a necessidade da atuação tanto dos que aprendem, como dos que ensinam, enquanto sujeitos ativos no processo da aprendizagem, e, principalmente, desenvolvedores do ato educativo. As palavras, para Freire, constituíam muito mais do que um elemento gráfico, elas representavam situações existenciais no processo de alfabetização e leitura. Como expressa Freire (2005, p. 36-37):

[...] o código é a representação de uma situação existencial, o descodificador tende a passar da representação à situação muito concreta, na qual e com a qual trabalha. Assim é possível explicar, por meio de conceitos, por que os indivíduos começam a portar-se de uma maneira diferente frente à realidade objetiva, uma vez que esta realidade deixou de apresentar-se como um beco sem saída e tomou o seu verdadeiro aspecto; um desafio a que os homens devem responder.

Para Freire (2013), a palavra pode ser refletida de modo problematizador entre professores e alunos, e a decodificação atingir um nível crítico de conhecimento, isso, se partirmos da experiência que o aluno traz. Por exemplo, quando o sujeito escreve mundo, ele não está apenas representando graficamente uma palavra qualquer, mas sim, percebendo as "relações entre os elementos da codificação e entre os fatos que a situação real apresenta, relações que antes não eram percebidas" (FREIRE, 2013, p. 36). 
A partir do exemplo supracitado, observamos que o educador ultrapassa os conhecimentos a respeito da apreensão da língua escrita de seu tempo, quando apresenta o método de alfabetização na perspectiva da leitura da palavra, articulada à leitura de mundo. Nesse método, o professor deve observar o que é significativo para os alunos, retirar as palavras do contexto dos estudantes para alfabetizá-los e fazer uso do diálogo para convidá-los a refletir sobre diferentes situações, como a busca pela autonomia. A abordagem de Freire não utiliza o estudo mecânico das sílabas, como defendido pelos métodos tradicionais de alfabetização (métodos sintéticos e analíticos). Ademais, a aprendizagem da leitura e a alfabetização são atos de educação e a educação é um ato fundamentalmente político.

\section{O conhecimento sob a via moriniana}

O acesso e a sensação de domínio do conhecimento, apesar de suscitar dúvidas e brechas inexplicáveis, sinalizando incompletude e, não raro, erro e ilusão, tem se tornado um dos grandes desafios humanos, um dos objetivos a serem desejavelmente atingidos em sua plenitude. Contudo, chegamos hoje à compreensão de que qualquer tentativa de direcionamento rumo ao conhecimento integral torna-se rota de frustração, caminho inconcluso e contraditório, uma vez que todo saber é dinâmico, movente e transitório e, assim, continuamente processual, intrigante e provocador.

Incerteza e imprevisibilidade têm se tornado características constitutivas do inacabamento da concepção contemporânea de construção de conhecimento. A visão paradigmática newtoniano-cartesiana, ou mecanicista, presente atualmente em muitos contextos, embora tenha sido competente ao responder às indagações de/em um certo período de tempo histórico, tornou-se incapaz de contestar, de maneira satisfatória, os questionamentos da/na contemporaneidade, pois considera a inteireza, a totalidade, a existência de uma certeza e verdade tangíveis - o que se contrapõe ao pensamento e à concepção paradigmática emergentes que as tomam por inacabadas, incompletas. 
Nessa linha de pensamento destaca-se Morin (2020, p.15-16) e sua perspectiva complexa, argumentando que o conhecimento dos problemas essenciais e globais demanda a conexão dos saberes fragmentados, segmentados, dispersos pelo paradigma tradicional, mecanicista. Enfatiza que necessitamos de um conhecimento que saiba unir, articular saberes, apreendendo-lhes a complexidade e, não, a totalidade, pois "estamos condenados à incompletude" (p.16).

Sob a perspectiva complexa, o conhecimento está em construção contínua, sempre à procura de ir além, de transcender o conhecido, desafiando, colocando descobertas em xeque por entendê-las temporárias, carentes de serem testadas, aprovadas ou descartadas, gerando confirmações ou novas provocações que demandam, essas, futuras pesquisas e elaborações. O caminho do conhecimento é entendido como não linear e não isento de percalços: as vias complexas do saber, rizomáticas, compreendem riscos de erros e ilusões que podem causar cegueiras do conhecimento. Como adverte Morin (2000, p.19), "o maior erro seria subestimar o problema do erro; a maior ilusão seria subestimar o problema da ilusão", uma vez que a distinção entre elas seria "ainda mais difícil porque o erro e a ilusão não se reconhecem, em absoluto, como tal."

Por não ser estável e por potencialmente comportar erros e ilusão, o conhecimento precisa ser compreendido como provisório, em contínuo desenvolvimento. Seu caráter processual, de atemporalidade, contempla uma constante necessidade de investigação, de mirada transversal e transdisciplinar, articulando concepções recentes às já estabelecidas para construir significados, objetiva e subjetivamente, que possam ser elaborados e/ou traduzidos, pelo pensamento e pela linguagem, para transmitir diferentes percepções de mundo. A inter-relação recíproca entre as partes e o todo empresta à construção de conhecimento um sentido hologramático e recursivo que, sistemicamente, propõe uma conexão de complementaridade dialógica aos conceitos opostos, às contradições. Dessa forma, os operadores do pensamento complexo ${ }^{2}$, como destaca

2 Referimo-nos aos operadores ou princípios hologramático, recursivo, sistêmico e dialógico (MORIN, 2005, 2015). 
Morin (2013, p.187), se conectam à tessitura de saberes, edificando o "conhecimento que sabe contextualizar, globalizar, multidimensionalizar, ou seja, ser complexo". Uma reforma do conhecimento nessa direção caracteriza a reforma do pensamento a que Morin se refere em sua obra e, talvez, seja a fórmula que equacione a grande questão educacional: "não se pode reformar a instituição sem antes reformar as mentes, mas não se pode reformar as mentes sem antes reformar as instituições" (MORIN, 2013, p.191). A fórmula a que nos referimos e que percebemos sugerida na afirmação do autor, não pode estar pautada na hegemonia de uma instância ou na temporalidade de realização de uma ação específica, mas parece ser a que encontre, na possibilidade de articulação simultânea de ações entre as várias instâncias comprometidas, a sua alternativa de encaminhamento.

Segundo Morin (2000, p.23), a racionalidade pode, em alguma medida, proteger o conhecimento do erro e da ilusão. $\mathrm{O}$ autor destaca duas formas de racionalidade:

1. a racionalidade construtiva: que elabora teorias coerentes, verifica a lógica da organização teórica, a compatibilidade de ideias, a concordância de asserções e dados empíricos. Essa racionalidade permanece aberta ao que a contesta para evitar que se feche, tornando-se doutrina e se convertendo em racionalização; e

2. a racionalidade crítica: que atua nos erros e ilusões das crenças, doutrinas e teorias. Contudo, pode ainda comportar certa possibilidade de erro e ilusão, quando se corrompe e se transforma em racionalização.

Racionalidade e racionalização possuem convergências e divergências de sentido. A racionalização parece racional porque constitui um sistema lógico e perfeito, embasado na dedução ou indução; contudo, para Morin (2000, p. 23), fundamenta-se em bases mutiladas ou falsas, opondo-se à contestação de argumentos e à verificação empírica. A racionalização é fechada; a racionalidade é aberta. Apesar de praticamente se alimentarem nas mesmas bases, 
a racionalização representa uma das fontes mais poderosas de erros e ilusões, pois, ao contrário da racionalidade, não reconhece o amor, os sentimentos, os mistérios, o obscuro, o irracional. Morin (2000, p.23) esclarece que se "reconhece a verdadeira racionalidade pela capacidade de identificar suas insuficiências." Nesse sentido, a racionalidade contempla um caráter crítico.

Com base nos contrastes delineados, o paradigma mecanicista se enquadra como racionalizador, pois valoriza teorias verificáveis pela lógica dedutiva e indutiva, por ignorar o sujeito, a subjetividade, a afetividade. Inversamente, o pensamento complexo dialoga com o real e "opera o ir e vir incessante entre a instância lógica e a instância empírica; é o fruto do debate argumentado das ideias, e não a propriedade de um sistema de ideias" (MORIN, 2000, p.23). O pensamento complexo é aberto e reconhece o sujeito, seus sentimentos, seus enigmas. Emprega, portanto, a racionalidade.

Ao aprofundar sua argumentação sobre racionalização e racionalidade, Morin (2000, p.24) alerta:

Começamos a nos tornar verdadeiramente racionais quando reconhecemos a racionalização até em nossa racionalidade e reconhecemos os próprios mitos, entre os quais o mito de nossa razão toda-poderosa e do progresso garantido.

Daí decorre a necessidade de reconhecer na educação do futuro um princípio de incerteza racional: a racionalidade corre risco constante, caso não mantenha vigilante autocrítica quanto a cair na ilusão racionalizadora. Isso significa que a verdadeira racionalidade não é apenas teórica, apenas crítica, mas também autocrítica.

A recomendação do autor observa a proximidade semântica entre os conceitos abordados, indicando a relevância de escrutiná-los não apenas teórica e criticamente, mas também por meio da via reversa da autocrítica. O destaque dado aos movimentos teórico, crítico e autocrítico revelam, em nosso entender, um alerta para o desenvolvimento de um circuito, ou seja, um movimento circular recursivo, retroalimentador, que se inicia no observador teórico-crí- 
tico em direção ao objeto observado, dele voltando ao observador, em forma de autocrítica ou, em outras palavras, que se inicia no sujeito teórico-crítico em direção ao objeto do conhecimento e dele regressando ao sujeito, em forma de autocrítica, podendo, como circuito, desenvolver um percurso retroalimentador repetidas vezes, como ilustrado a seguir:

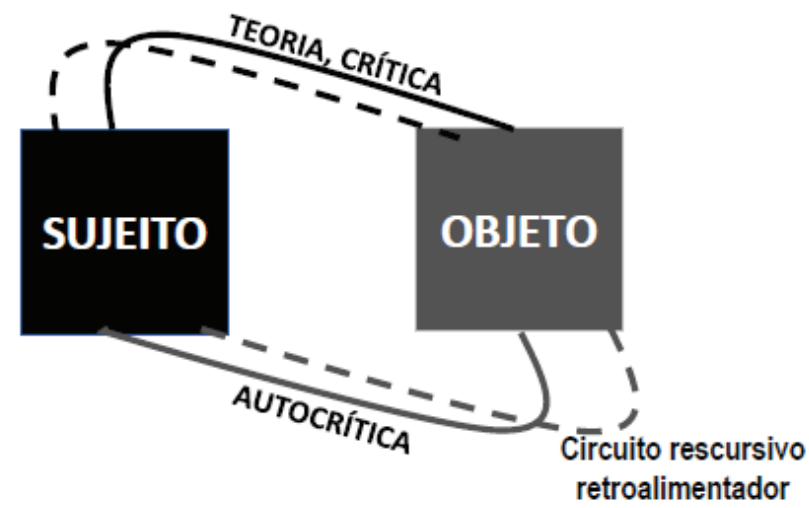

Figura 1: O princípio da incerteza racional

Fonte: As autoras

A Figura 1 representa nossa compreensão do princípio da incerteza racional (MORIN, 2000, p.24) e destaca que, apesar de usarmos a racionalidade, de sermos teórico-críticos ao abordarmos o objeto do conhecimento, nossa autocrítica não revela uma certeza incondicional (o que seria incoerente com o pensamento complexo), mas uma incerteza racional, pois a razão aberta, complexa, só poderia acarretar incertezas. O circuito recursivo retroalimentador, sugerido por Morin e por nós assim nomeado para caracterizar o princípio da incerteza racional, nos induz à reflexão de que a crítica, sem autocrítica, se esvazia: torna-se um caminho de mão única no qual a racionalidade (e a criticidade) só é usada para escrutinar o outro, sem ter olhos para si, sem reflexo no si-mesmo, correndo o risco de tornar-se racionalização. Essa percepção empresta à crítica uma lei- 
tura ímpar, pois a concebe em seu caráter recursivo, de retro-ação, de ida (crítica) e volta (autocrítica), ressaltando a racionalidade e a incerteza racional implicadas no processo.

Morin (2011) também afirma que o princípio da incerteza racional desconstrói um pretenso determinismo, uma vez que os efeitos desejados para uma ação não são, sempre, os produzidos. Essa constatação define o conceito de ecologia da ação, indicando que um sistema complexo, multidimensional, apresenta características probabilísticas que nos fazem conviver com o risco de consequências inesperadas. Não há linearidade causal (i.e., causa -> efeito), mas indeterminismo. A convivência com incertezas conscientiza do inacabamento e sinaliza para a existência de um contínuo devir.

Em face da argumentação apresentada, retomarmos os caminhos do conhecimento e sua vulnerabilidade ao erro e ilusão, articulados à racionalidade e às incertezas racionais, para refletir sobre a noção de conhecimento pertinente. Segundo Morin (2013, p.197),

Um conhecimento não é mais pertinente porque contém um número maior de informações, ou porque é organizado da forma mais rigorosa possível sob uma forma matemática; ele é pertinente se souber situar-se em seu contexto e, mais além, no conjunto ao qual está vinculado.

Partindo dessa explicação, apreendemos que o conhecimento pertinente se situa em um contexto específico, a ele perfeitamente integrado, ou seja, ecologizado, sendo capaz de compreender os problemas fundamentais e globais para neles inscrever os conhecimentos parciais e locais. Como acentua Morin (2003, p.15), o conhecimento pode não progredir por sofisticação, formalização e abstração, mas certamente, floresce pela capacidade de contextualizar e englobar. Nesse sentido, o conhecimento pertinente torna-se fundamental, pois, no nosso entender e de acordo com nossa nomeação, atua como um agente ecologizador, ligando/religando saberes consolidados a informações recentes para situá-los em seus devidos contextos e nos conjuntos a que pertencem. 
Essa aptidão para contextualizar e globalizar gera a emergência de um pensamento ecologizante (MORIN, 2003, p.25) que estabelece inseparabilidade entre acontecimentos, informações ou conhecimentos e meio ambiente (cultural, econômico, social, político e natural). Esse pensamento é, inegavelmente, complexo porque sempre procura relações e inter-retro-ações entre cada fenômeno e seu contexto, conexões de reciprocidade entre todo/partes, e reconhecimento recíproco da unidade na diversidade.

Morin (2018, p.72) atribui importância ao pensar complexo também pelo fato de, considerando objetividade e subjetividade, reconhecer a qualidade poética da vida. O autor (MORIN, 2018, p.54) metaforicamente contrapõe poesia e prosa, e argumenta:

A poesia tem seu papel de introdutora às dimensões poéticas e estéticas da vida. Porque a poesia não é unicamente uma coisa que se escreve, que se recita. É uma realidade da vida, que tem sentido na intensidade dos afetos e dos sentimentos que proporcionam exaltação, amor, alegrias, gozos, como se veem em tantas oportunidades. Poesia é viver de verdade. Prosa é apenas sobreviver. Tantas pessoas são obrigadas a assumir uma quantidade tão grande de prosa em sua vida que não vivem, sobrevivem.

À luz do paradigma mecanicista, simplificador, a citação de Morin poderia nos fazer supor que suprimir a poesia, ou reprimir a afetividade, implicaria eliminar a possibilidade de erro e ilusão, pois estaríamos extinguindo a influência de fatores subjetivos que poderiam repercutir na capacidade de pensar e construir conhecimento. Contrariamente, sob a perspectiva do pensamento complexo, juízos e visões unilaterais podem induzir ao erro e à ilusão pois, ao realçar uma possibilidade, a outra naturalmente ficaria excluída ou enfraquecida (i.e., poesia ou prosa; afetividade ou frieza) e, assim, se restringiria a perspectiva de escolhas, os contextos e conjuntos de potenciais ligações/religações para a emergência do conhecimento.

Se voltarmos à citação, temos que poesia é vida e prosa é sobrevivência, como afirma Morin; ou seja, de uma certa forma, vive-se também de prosa, embora sem os tons e a leveza que a poesia 
poderia acrescentar à vida. Morin (2000, p.20), usando de sua incerteza racional, também assegura que a afetividade tanto pode "asfixiar" como "fortalecer" o conhecimento, indicando que a presença de um sentimento tanto pode ter uma repercussão positiva como desastrosa. Compreendemos, então, que o paradigma simplificador é polar e excludente, no sentido de forçar uma escolha, limitando-a à dualidade apresentada (i.e., prosa ou poesia). O pensamento complexo, por outro lado, é agregador, indicando que ambas as alternativas poderiam ser viáveis, dependendo do contexto (i.e., prosa e poesia).

A proposta mais significativa - e, na nossa opinião, mais ousada - da concepção moriniana é, sem dúvida, a de uma reforma do pensamento. De acordo com Morin (2003, p.20), ela contemplaria uma reformulação que envolveria o emprego da inteligência para responder a desafios de várias naturezas (e.g., cultural, sociológico, cívico, entre outros); seria uma "reforma não programática, mas paradigmática, concernente a nossa aptidão para organizar o conhecimento."

Morin (2003, p.24) considera "uma cabeça bem-feita" aquela capaz de organizar conhecimentos - conhecimentos pertinentes - e, assim, evitar uma acumulação improdutiva. Para o autor (op.cit.),

Todo conhecimento constitui, ao mesmo tempo, uma tradução e uma reconstrução, a partir de sinais, signos, símbolos, sob a forma de representações, ideias, teorias, discursos. A organização dos conhecimentos é realizada em função de princípios e regras; comporta operações de ligação (conjunção, inclusão, implicação) e de separação (diferenciação, oposição, seleção, exclusão). O processo é circular, passando da separação à ligação, da ligação à separação, e, além disso, da análise à síntese, da síntese, à análise. Ou seja: o conhecimento comporta, ao mesmo tempo, separação e ligação, análise e síntese.

Nossa civilização e, por conseguinte, nosso ensino privilegiaram a separação em detrimento da ligação, e a análise em detrimento da síntese. Ligação e síntese continuam subdesenvolvidas. E isso, porque a separação e a acumulação sem ligar os acontecimentos são privilegiadas em detrimento da organização que liga os conhecimentos. 
A citação acima contempla uma visão aberta de conhecimento, pois o autor o dimensiona como tradução e reconstrução, processos que se iniciam após a recepção de um input (e.g., sinais, signos, símbolos, discursos), sucedido pela ação de um componente subjetivo, individual (e.g., representações, teorias, conhecimentos prévios), responsável pela ressignificação da informação inicial que, passando por princípios organizadores, poderá encontrar seu contexto e conjunto para ser adequadamente armazenado.

O trecho citado ainda aborda dois aspectos conflitantes: em primeiro lugar, Morin detalha a construção e organização de conhecimento, enfatizando que, ao mesmo tempo, esse processo comporta operações contraditórias: separação e ligação, análise e síntese. Em segundo lugar, comenta que a construção e a organização, atualmente, priorizam a separação e a análise. Nesse caso, trata-se de um conhecimento que se fragmenta em disciplinas estanques - um dos traços marcantes do paradigma mecanicista, ainda vigente em diversos contextos educacionais. Para o autor (MORIN, 2003, p.25), o conflito existente não se resolve com a abertura das fronteiras interdisciplinares, mas com a mudança daquilo que as gera, isto é, dos princípios organizadores do conbecimento.

Morin (2003, p.88-89) explicita que tais princípios abrangem um pensamento que:

- compreende o conhecimento das partes como reciprocamente dependentes do conhecimento do todo;

- reconhece e examina fenômenos multidimensionais, sem isolar ou mutilar cada uma de suas dimensões;

- reconhece e trata as realidades, ao mesmo tempo, solidárias e conflitantes;

- $\quad$ respeita a diversidade, enquanto reconhece a unidade.

Esses princípios são os operadores cognitivos da complexidade, caracterizada por uma causalidade circular, indicadora de que os efeitos retroagem às causas e o caminho de construção do conhecimento é recursivo. Esse percurso não é segmentado e cada parte que o compõe está refletida no todo, assim como esse está refletido nas 
partes que o formam. Trata-se de um processo sistêmico, relacional, multidimensional, no qual a unidade se harmoniza com a diversidade, e os opostos compartilham uma relação de complementaridade.

A descrição sintetizada acima revela que a complexidade, alicerce da reforma do pensamento a que Morin aspira, representa uma oposição ao paradigma mecanicista enquanto, simultaneamente, dele se alimenta para sinalizar vias inéditas para a construção de conhecimento, valorizando, sobretudo, a incerteza, a imprevisibilidade, as relações recíprocas entre todo e partes, a complementaridade das contradições, a multidimensionalidade dos fenômenos, a unidade na diversidade, a não linearidade, a não fragmentação e a transdisciplinaridade.

Sinalizando tais vias, o pensamento complexo contempla, então, o sujeito relacional cuja tessitura também considera incertezas, ambiguidades, imprevisibilidades, contradições. É o sujeito autônomo/dependente, pois não é totalmente independente "de seu meio ambiente, seja ele biológico, cultural ou social” (MORIN, 2003, p.118). É o sujeito planetário que, ao mesmo tempo, explora sua racionalidade e afetividade; que se constrói, desconstrói, reconstrói; ciente de sua inconclusão, da incompletude do seu saber, mas que segue sempre buscando conhecer mais.

\section{O encontro das vias: no diálogo, a continuidade de construção de conhecimento}

Freire: Dizem que somos convergentes e divergentes...

Morin: Sim. Acredito que tenhamos um ponto comum, pois pensamos em construção e, não, em transmissão de conhecimento. $\mathrm{O}$ conhecimento é inacabado. Temos consciência da incompletude do ser e do saber, ao mesmo tempo em que temos uma ânsia pela totalidade, embora saibamos não ser possível atingi-la.

Freire: De fato, rompemos com o paradigma mecanicista. Conhecer é desocultar, é ganhar compreensão cada vez mais exata de um objeto, é perceber as relações entre um objeto e os outros, é correr riscos, é a aventura de criar e recriar.

Morin: Também percebo o conhecimento como relacional. Além disso, 
vejo-o como sistêmico: um conjunto de partes interligadas, que refletem o todo e nele estão refletidas. O conhecimento é dinâmico, vivo, complexo. Freire: $\mathrm{O}$ conhecimento engloba muitos aspectos da vida: a razão, a emoção, a amorosidade...

Morin: A poesia, a prosa... o erro, a ilusão, as incertezas...

Freire: O mundo também! É pleno de tudo! É esse mundo que gostaria que meu aluno lesse e compreendesse. Ler o mundo, com o mundo, no mundo. Morin: Mas a educação me parece cega quanto ao que é conhecimento. Não se preocupa em conhecer o conhecimento. Cabeça bem-feita ou cabeça bem cheia? Nós dois propusemos uma ruptura paradigmática, mas ainda vemos que grande parte das escolas continua perpetuando o tradicional. Precisamos de uma reforma do pensamento e da educação.

Freire: Acredito muito no diálogo. Mas ele não existe sem um profundo amor ao mundo e aos homens. Não há diálogo verdadeiro sem um pensar verdadeiro, pensar crítico, pensar que, não aceitando a dicotomia mundo-homens, reconheça entre eles uma inquebrantável solidariedade. Diálogo é uma exigência existencial, é o encontro solidário entre refletir e agir. É por meio dele que se torna possível superar a contradição educador-educandos, tornando-os companheiros.

Morin: Para mim, compreensão envolve um movimento hermenêutico, recursivo, que, quando posto em crítica, me faz refletir sobre a necessidade de crítica e autocrítica, como oscilação reversa e como uma forma de me relacionar ao outro, ao objeto da crítica. Os dois conceitos estão intimamente interligados e me parece que precisam ser tecidos juntos.

Freire: Talvez a conexão dos dois se faça pelo diálogo, pelo ensino crítico que demanda uma forma crítica de compreender e realizar a leitura da palavra e do mundo: a palavramundo. A palavra transforma o mundo, uma vez que contempla duas dimensões: ação e reflexão. Precisamos problematizar, conscientizar, libertar, transformar. Necessitamos do empoderamento da Pedagogia Crítica.

Morin: Vejo semelhanças entre sua forma de pensar e a minha. Tudo me parece uma grande teia que se enreda no conhecimento: de mundo, diz você; pertinente, digo eu.

Freire: Sim, o conhecimento que emancipa, que liberta.

Morin: O conhecimento que é tecido junto, recursivamente; que engloba as imprevisibilidades, as incertezas; que forma o cidadão complexo, planetário. Freire: ... que forma o cidadão autônomo, o cidadão político.

Morin: Mas... se não estamos na mesma via, estamos em uma muito próxima.

Freire: Concordo! 
O diálogo acima, naturalmente fictício, foi criado a partir da intertextualidade de vozes e pensamentos dos autores em foco, ora retomando suas palavras textualmente (sem querer assumir-lhes a autoria), ora criando aquelas que nossa imaginação nos levou a crer que verbalizariam para construir uma reflexão mais próxima do que se poderia denominar final para um artigo. A motivação foi, inegavelmente, a curiosidade de vê-los conversando: dois pensadores sagazes, observadores do mundo, ansiosos pela busca de melhores condições humanas para o educador, o educando, o ser humano: o cidadão autônomo, empoderado, político, na visão de Freire; o cidadão complexo e planetário, na concepção de Morin.

Simulando suas vozes, lançamos mão do diálogo para retomar conceitos discutidos no artigo, promovendo a recursividade moriniana e propondo um repensar hermenêutico que reforçasse um argumento, promovendo acordo ou contestação. Como os autores em questão, acreditamos que conflitos também podem ser constituintes da construção de conhecimentos.

Se, ao longo do artigo, dialogamos com os autores em separado, apresentando seus conceitos, comentando-os e ilustrando-os, ao final, abrimos espaço para que suas próprias vozes emergissem (ainda que por meio das nossas), oportunizando que defendessem seus pontos de vista e que, por meio de uma tessitura lexical diferenciada, pudessem evidenciar algumas de suas semelhanças e diferenças, mas, acima de tudo, sua compatibilidade, sua complementaridade. Esperamos que este formato tenha contribuído para enredar uma teia dinâmica na qual fique evidente que a emancipação do ser humano se embasa na palavra, no mundo; na leitura do mundo, com o mundo, incerto e contraditório; em circuitos recursivos de conhecimentos pertinentes que promovem transformação e libertação do cidadão político, garantindo a sua cidadania terrena.

\section{Referências}

FREIRE, Paulo. A importância do ato de ler: em três artigos que se completam. São Paulo: Cortez: Autores Associados, 1992. 
FREIRE, Paulo. Pedagogia da autonomia: Saberes necessários à prática educativa. 35. Ed. São Paulo: Paz e terra, 1999.

FREIRE, Paulo. A educação do futuro. O Globo, Rio de Janeiro, Caderno Prosa \& Verso, 24 maio 1997.

FREIRE, Paulo. Educação como Prática da Liberdade. 28. Ed. Rio de Janeiro: Paz e Terra. 2005.

FREIRE, Paulo. Pedagogia do Oprimido. 32. Ed. Rio de Janeiro: Paz e terra, 2013.

FREIRE, Ana Maria Araújo. Cadernos. Cedes, Campinas, v. 35, n. 96, p. 291-298, maio-ago., 2015.

MORIN, Edgar. Os sete saberes necessários à educação do futuro. São Paulo: Cortez, Brasília: Edições UNESCO, 2000.

MORIN, Edgar. A cabeça bem-feita: repensar a reforma, reformar o pensamento. Rio de Janeiro: Bertrand Brasil, 2003.

MORIN, Edgar. Introdução ao pensamento complexo. Porto Alegre: Editora Sulina, 2005.

MORIN, Edgar. Ética e sociedade. In: A. Pena-Vega, C. R.S. Almeida, I. Petraglia (orgs.), Edgar Morin: ética, cultura e educação. São Paulo: Cortez Editores, 2011.

MORIN, Edgar. A via para o futuro da humanidade. Rio de Janeiro: Bertrand Brasil, 2013.

MORIN, Edgar. Ensinar a viver: manifesto para mudar a educação. Porto Alegre: Editora Sulina, 2015.

MORIN, Edgar. Fórum de estudos do homem e da vida. In: M. C. Almeida, M. K. S. Reis, F, França (orgs.), Edgar Morin: conferências na cidade do sol - Natal/ Brasil (1989 a 2012). Natal: EDUFRN, 2018.

MORIN, Edgar. Conhecimento, ignorância, mistério. Rio de Janeiro: Bertrand Brasil, 2020. 